\title{
Degradação de pastagem avaliada por atributos físicos do solo de fácil obtenção analisados por geoestatística
}

\section{Célia Regina Grego ${ }^{1}$, Cristina Aparecida Gonçalves Rodrigues ${ }^{2}$, Sidney Rosa Vieira ${ }^{3}$, Alessandra Gonçalves Kobayashi e André Luiz dos Santos Furtado ${ }^{5}$}

\author{
1 Agrônoma, Pesquisadora na Embrapa Monitoramento por Satélite, Campinas - SP, \\ crgrego@cnpm.embrapa.br \\ Zootecnista, Pesquisadora na Embrapa Monitoramento por Satélite, Campinas - SP, \\ crisagr@cnpm.embrapa.br \\ ${ }^{3}$ Agrônomo, pesquisador no Instituto Agronômico de Campinas, Campinas - SP, sidney@iac.sp.gov.brl \\ ${ }^{4}$ Graduanda em Engenharia Ambiental, Bolsista PIBIC CNPq da Embrapa Monitoramento por Satélite, \\ alessandra@cnpm.embrapa.br \\ ${ }^{5}$ Biólogo, Pesquisador na Embrapa Monitoramento por Satélite, Campinas - SP, andre@cnpm.embrapa.br
}

\begin{abstract}
Resumo - A estrutura física do solo é um dos principais indicativos relacionados à degradação das pastagens. Este trabalho teve o objetivo de avaliar níveis opostos de degradação de pastagens de Brachiaria localizadas no município de Guararapes (SP), a partir da análise da variabilidade espacial de alguns atributos físicos do solo de fácil obtenção. Os atributos físicos do solo foram avaliados na pastagem não degradada e degradada. No solo com pastagem degradada houve redução da infiltração de água medida a $10 \mathrm{~cm}$ comparada com o solo sob pastagem não degradada. Para a área com pastagem degradada, tanto a infiltração de água no solo, quanto os atributos referentes a resistência do solo à penetração apresentaram estrutura de dependência espacial. Na pastagem não degradada também houve dependência espacial para a infiltração de água no solo, mas para a resistência à penetração houve dependência somente nas camadas mais profundas de $20-40 \mathrm{~cm}$. A distribuição espacial observada nos mapas indica que é possível usar mapas de atributos do solo para selecionar locais onde se pode identificar a degradação de pastagem.
\end{abstract}

Palavras-chave: Brachiaria; infiltração de água; resistência à penetração.

\section{Degradation of pasture evaluated by physical attributes of soil easily obtained analyzed by geostatistics}

\begin{abstract}
The physical structure of soil is one of the main indications related to degradation of pastures. This study aimed to available the opposite levels of degradation of Brachiaria in Guararapes, Brazil, from the spatial variability of some soil physical attributes easy to obtain. The physical attributes of soil were evaluated to pasture no degraded and degraded. In the degraded pasture caused a reduction in the infiltration of soil water measured at $10 \mathrm{~cm}$ compared with the no degraded pasture. For the degraded pasture area both water infiltration into the soil, as the attributes for the resistance to penetration showed spatial dependence structure. In the pasture no degraded was also spatial dependence of soil water infiltration but for the resistance to penetration was dependent only on the deeper layers of $20-40 \mathrm{~cm}$. The spatial distribution observed in the maps indicates that is possible to use maps of soil attributes to select places where one can identify the degradation of pasture.
\end{abstract}

Key words: Brachiaria; water infiltration; resistance to penetration.

\section{Introdução}

A estrutura física do solo é um dos principais indicativos relacionados à degradação das pastagens que pode ser provocada pelo pastejo excessivo nas áreas.

Lanzanova et al. (2007) verificaram efeito de diminuição da infiltração de água no solo quando reduziram o intervalo entre pastejos de 28 para 14 dias. Efeito semelhante foi observado por Miguel et al (2009), em função da variabilidade espacial da intensidade de pisoteio. A variabilidade espacial das propriedades dos solos pode ocorrer tanto horizontalmente quanto verticalmente, decorrente de sua origem, localização, tipo 


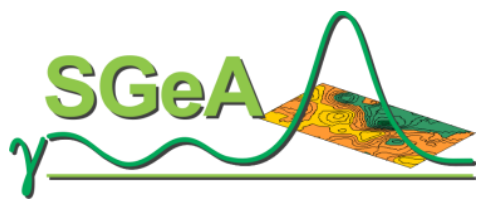

ou manejo. Neste mesmo sentido, Souza et al. (2006) mostraram que, em latossolos, em áreas de formas côncavas e convexas, independentemente do histórico de manejo, há mais variabilidade de propriedades químicas e físicas do que em áreas de formas lineares.

Portanto, para a adequada caracterização das propriedades do solo é importante considerar sua variabilidade espacial. Uma das formas de se avalisar a variabilidade espacial das propriedades do solo é com o uso de geoestatistica, uma ferramenta adequada e fundamental para a análise de propriedades que variem de um local para outro com algum grau de organização ou continuidade, expresso através da dependência espacial (VIEIRA, 2000).

Este trabalho teve o objetivo de avaliar níveis opostos de degradação de pastagens e a variabilidade espacial dos atributos físicos do solo de fácil obtenção em pastagens do município de Guararapes (SP) no extremo oeste do Estado de São Paulo.

\section{Material e Métodos}

O trabalho foi conduzido em pastagens formadas com a gramínea Brachiaria, localizadas no município de Guararapes (SP), com posição geográfica definida pelas coordenadas $21^{\circ} 16^{\prime} 35^{\prime \prime}$ de latitude sul e $50^{\circ} 37^{\prime} 00^{\prime \prime}$ de longitude oeste e com altitude média de 398 metros.

O clima de Guararapes, segundo a classificação climática de Köpen, é do tipo Aw, verão quente, tropical chuvoso com inverno seco. Os solos predominantes são Latossolo Vermelho amarelo e Argissolo (Segundo Embrapa, 1999).

As pastagens foram previamente caracterizadas em campo quanto aos níveis de degradação das pastagens. A determinação dos níveis de degradação das pastagens seguiu a classificação adaptada de Nascimento Júnior et al. (1994) considerando duas condições extremas de nível de degradação das pastagens, não degradado e degradado. O não degradado apresenta alta densidade e cobertura de solo pela pastagem, e o degradado apresenta condição oposta.

Em dezembro de 2010, foi realizada a amostragem de solo para a caracterização dos atributos físicos nos níveis de degradação das pastagens, em trinta pontos da área total de cada piquete (aproximadamente $3 \mathrm{ha}$ ). Em cada ponto, foi determinada a taxa de infiltração tridimensional de água no solo saturado, na profundidade de $10 \mathrm{~cm}$. A infiltração tridimensional considera as componentes direcionais dos fluxos na vertical, horizontal e no declive. Para tanto, abriu-se um orifício no solo, com um trado holandês, até a profundidade desejada, e mediu-se a taxa de infiltração de água em cada ponto com o permeâmetro modelo IAC (VIEIRA, 1998), obtendo-se a taxa de infiltração constante em $\mathrm{mm} \cdot \mathrm{h}^{-1}$

A resistência à penetração também foi obtida como um indicador físico da compactação do solo, utilizando-se o penetrômetro de impacto (Stolf, 1991) e calculou-se a resistência (MPa) para camada da superfície até $40 \mathrm{~cm}$ de profundidade.

Inicialmente os dados foram analisados pela estatística descritiva e para verificação da dependência espacial, interpolação dados e construção de mapas foi empregada análise geoestatística conforme Vieira (2000). Foram construídos e ajustados semivariogramas, partindo das pressuposições de estacionariedade da hipótese intrínseca e do cálculo da semivariância $\chi(\mathrm{h})$ estimada na equação 1 :

$\gamma(\mathrm{h})=\frac{1}{2 N(h)} \sum_{i=1}^{N}\left[Z\left(x_{i}\right)-Z\left(x_{i}+h\right)\right]^{2}$

onde $N(h)$ é o número de pares dos valores medidos $Z\left(x_{i}\right), Z\left(x_{i}+h\right)$, separados por um vetor $h$.

Os semivariogramas que apresentaram dependência espacial foram ajustados a um modelo onde foram definidos os parâmetros do semivariograma: $\mathrm{C}_{0}=$ efeito pepita, $\mathrm{a}=$ alcance, $\mathrm{C}_{0}+\mathrm{C}_{1}=$ patamar e $\mathrm{C}_{1}=$ variância estrutural.

Observada a existência de dependência espacial definida pelo semivariograma, os valores vizinhos semelhantes possibilitaram estimar valores para qualquer local onde a variável não foi medida usando-se a krigagem, conforme Vieira (2000), que estima valores com as condições de estimativa sem tendenciosidade e com desvios mínimos em relação aos valores conhecidos, ou seja, com variância mínima. O programa KRIGE desenvolvido por Vieira et al. (2002) interpola por krigagem valores no espaço amostrado para qualquer posição. Com os valores estimados por krigagem foram construídos mapas de isolinhas em função da coordenada geográfica no programa Surfer 7.0 (GOLDEN SOFTWARE, 1999).

\section{Resultados e Discussão}

Os resultados da estatística descritiva estão na tabela 1. Verifica-se que no nível não degradado da pastagem, a média da infiltração de água foi maior, o que era de se esperar, pois no solo com pastagem 
degradada, a superfície do solo está mais compactada devido ao pisoteio dos animais ocorrendo redução da infiltração de água no solo medida a $10 \mathrm{~cm}$. Este resultado está de acordo com Miguel et al. (2009) onde concluíram que a taxa de infiltração de água no solo diminui com a intensidade de pisoteio.

Para o atributo resistência á penetração, o número de batidas para o penetrômetro atingir os $40 \mathrm{~cm}$ de profundidade foi maior no solo com pastagem degradada comparada com a não degradada, porém os valores médios de resistência à penetração por camadas de $10 \mathrm{~cm}$ não indicaram esta mesma tendência. $A$ resistência à penetração só foi maior na pastagem degradada nas camadas acima de $20 \mathrm{~cm}$ de profundidade. Isto pode ter sido influência da umidade do solo, pois no momento da medição, o solo encontrava-se com umidade elevada (maior do que 30\%) devido à grande precipitação ocorrida um dia antes.

Considerando-se a classificação proposta por Gomes (2000), os parâmetros estatísticos da infiltração indicaram alta variabilidade nos dados, com coeficientes de variação (CV) altos ( $>30 \%)$ (Tabela 1), já para a resistência à penetração a maioria foi menor do que $30 \%$. Os valores de assimetria e curtose, na maioria foram próximos de 0 e mostram que a distribuição dos resultados apresentou normalidade, com exceção da infiltração no nível não degradado e para número de batidas e resistência à penetração de $30-40 \mathrm{~cm}$.

Tabela 1. Estatística descritiva das variáveis: infiltração de água no solo a $10 \mathrm{~cm}$ de profundidade; número de batidas para o penetrômetro atingir a profundidade de $40 \mathrm{~cm}$; resistência a penetração (RP) nas camadas de $0-10,10-20,20-30,30-40 \mathrm{~cm}$

\begin{tabular}{|c|c|c|c|c|c|c|c|c|c|}
\hline Variáveis & Média & Mediana & $\begin{array}{l}\text { Coeficiente } \\
\text { de Variação }\end{array}$ & Variância & Mínimo & Máximo & Curtose & Assimetria & Contagem \\
\hline \multicolumn{10}{|c|}{ Pastagem não degradada } \\
\hline Infiltração a & & & & & & & & & \\
\hline $10 \mathrm{~cm}$ & 14,50 & 13,84 & 61,93 & 80,62 & 2,21 & 44,27 & 2,99 & 1,32 & 30,00 \\
\hline batidas (RP) & 12,40 & 12,00 & 16,77 & 4,32 & 8,00 & 17,00 & $-0,14$ & $-0,11$ & 30,00 \\
\hline $\mathrm{RP} 0-10 \mathrm{~cm}$ & 1,89 & 1,86 & 24,34 & 0,21 & 1,10 & 2,85 & $-0,69$ & 0,28 & 30,00 \\
\hline $\mathrm{RP} 10-20 \mathrm{~cm}$ & 2,53 & 2,51 & 26,48 & 0,45 & 1,33 & 3,98 & $-0,39$ & 0,18 & 30,00 \\
\hline RP $20-30 \mathrm{~cm}$ & 2,42 & 2,44 & 20,25 & 0,24 & 1,27 & 3,57 & 0,29 & 0,01 & 30,00 \\
\hline RP $30-40 \mathrm{~cm}$ & 2,00 & 2,00 & 30,50 & 0,37 & 0,91 & 3,17 & $-0,98$ & 0,27 & 30,00 \\
\hline \multicolumn{10}{|c|}{ Pastagem degradada } \\
\hline $\begin{array}{c}\text { Infiltração a } \\
10 \mathrm{~cm}\end{array}$ & 8,42 & 7,75 & 51,06 & 18,45 & 2,21 & 19,92 & 0,23 & 0,59 & 30,00 \\
\hline $\begin{array}{l}\text { Numero de } \\
\text { batidas (RP) }\end{array}$ & 13,07 & 13,00 & 29,15 & 14,48 & 7,00 & 27,00 & 5,45 & 1,65 & 30,00 \\
\hline $\mathrm{RP} 0-10 \mathrm{~cm}$ & 1,55 & 1,51 & 16,13 & 0,06 & 1,06 & 2,07 & $-0,55$ & 0,21 & 30,00 \\
\hline $\mathrm{RP} 10-20 \mathrm{~cm}$ & 2,34 & 2,25 & 34,19 & 0,23 & 1,40 & 3,61 & 1,30 & 0,95 & 30,00 \\
\hline $\mathrm{RP} 20-30 \mathrm{~cm}$ & 2,65 & 2,51 & 26,79 & 0,51 & 1,50 & 4,27 & $-0,50$ & 0,49 & 30,00 \\
\hline $\mathrm{RP} 30-40 \mathrm{~cm}$ & 2,45 & 2,22 & 55,10 & 1,81 & 1,04 & 8,33 & 12,47 & 3,05 & 30,00 \\
\hline
\end{tabular}

A análise geoestatística por meio da construção dos semivariogramas permitiu verificar a presença de dependência espacial nas propriedades analisadas, a partir do ajuste do modelo matemático que melhor ilustrasse o comportamento espacial da variável em função da distância. Todos os semivariogramas que apresentaram patamares definidos e ajustaram-se a um tipo de modelo estão na Figura 1.

Das variáveis estudadas, no nível da pastagem não degradada, a infiltração de água no solo a $10 \mathrm{~cm}$, o número de batidas, a resistência à penetração nas camadas de $20-30$ e de $30-40 \mathrm{~cm}$ apresentaram dependência espacial. No nível degradado da pastagem todas as variáveis estudadas apresentaram dependência espacial. Verifica-se que o modelo predominante é o esférico. Segundo Vieira (2000), o modelo matemático esférico é o que predomina nos trabalhos em ciência do solo. 


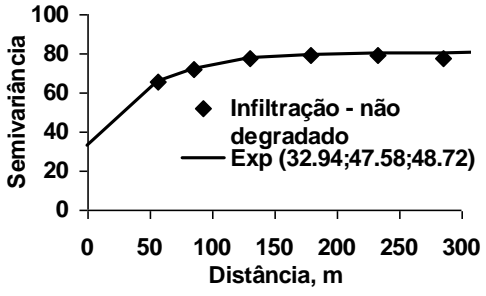

a

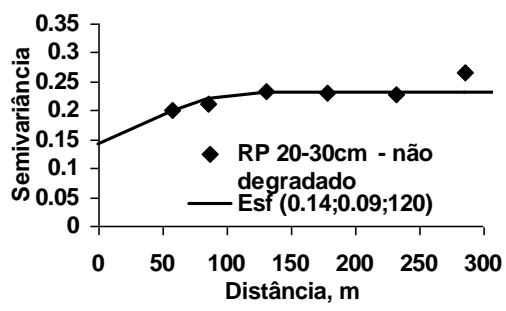

C

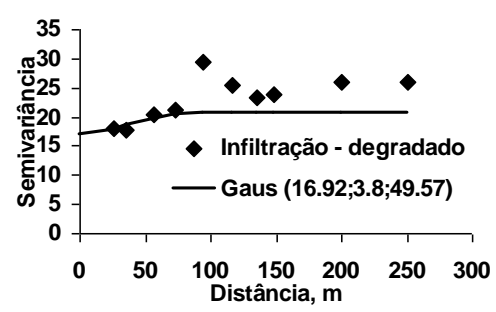

e

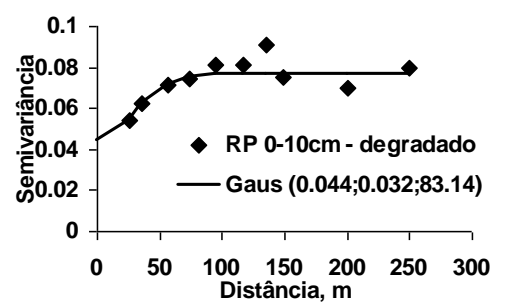

g

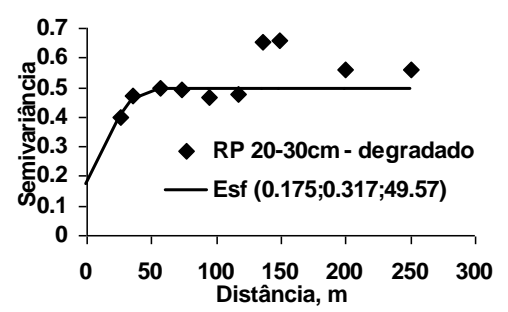

i

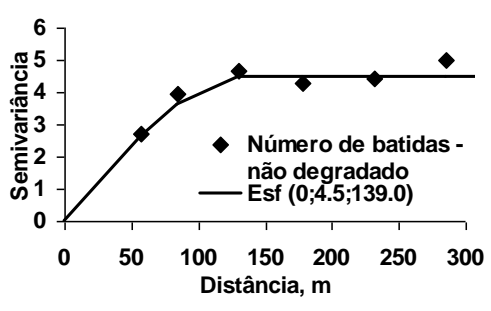

b

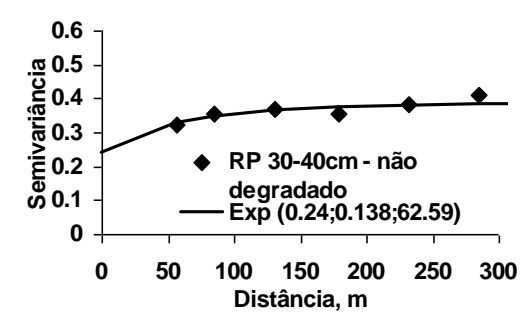

d

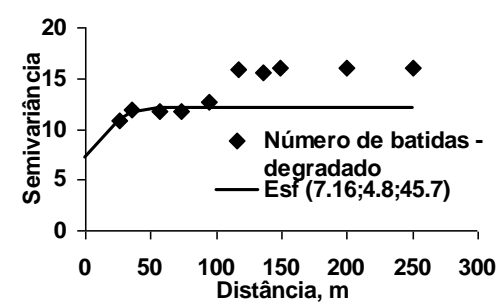

f

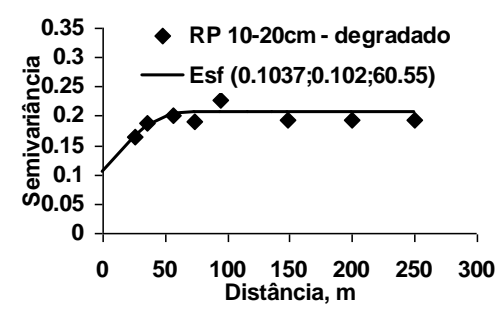

$\mathrm{h}$

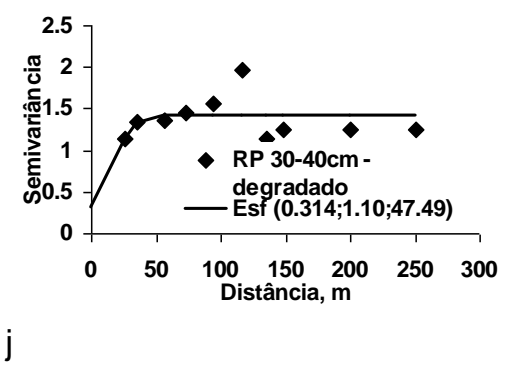

Figura 1. Semivariogramas ajustados pelos modelos Esféricos (Esf) gaussiano (Gaus) e Exponencial (Exp) para as variáveis que apresentaram dependência espacial no nível não degradado da pastagem: a - infiltração de água a $10 \mathrm{~cm}$; b - número de batidas; nas camadas; c - resistência à penetração de $20-30 \mathrm{~cm}$ e $\mathrm{d}$ - resistência à penetração de $30-40 \mathrm{~cm}$. No nível degradado da pastagem: e infiltração de água no solo a $10 \mathrm{~cm} ; \mathrm{f}$ - número de batidas; $\mathrm{g}$ - resistência a penetração $0-10 ; \mathrm{h}$ resistência a penetração de 10-20; i - resistência a penetração de 20-30; j - resistência a penetração de $30-40 \mathrm{~cm}$.

Os parâmetros dos modelos de semivariogramas ajustados foram utilizados para estimar valores de infiltração em locais não amostrados, por meio da krigagem ordinária (Figura 2). 

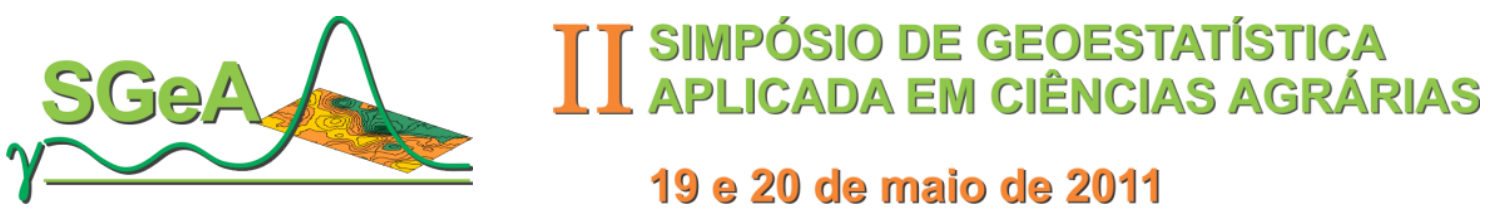

19 e 20 de maio de 2011

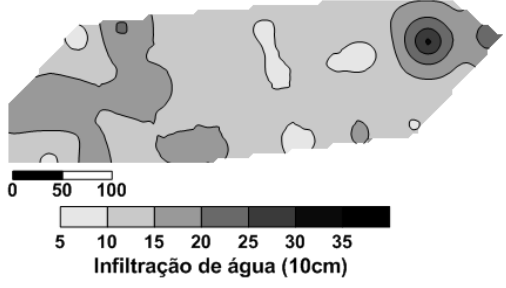

a - Não degradado

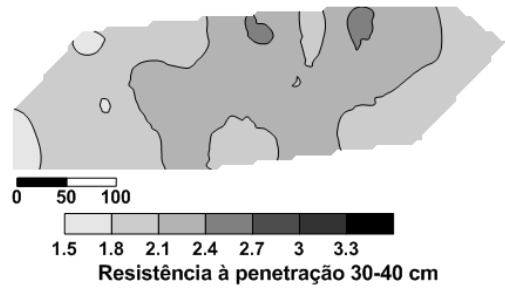

d - Não degradado

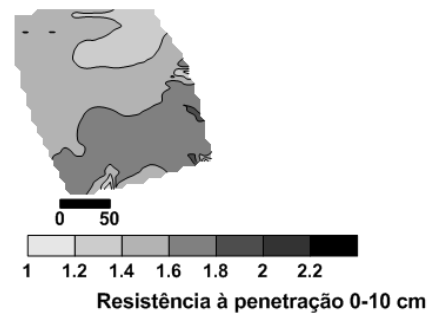

g - Degradado

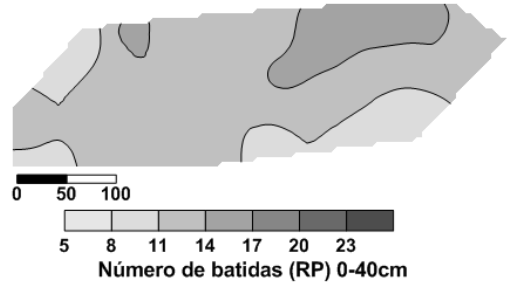

b- Não degradado

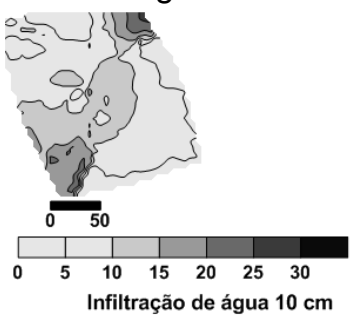

e- Degradado

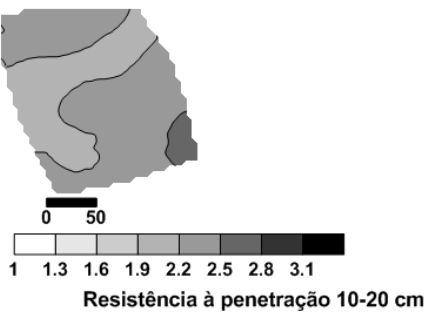

h - Degradado

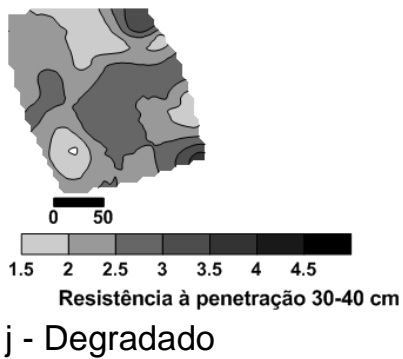

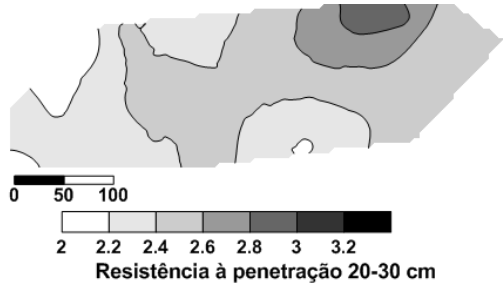

c - Não degradado

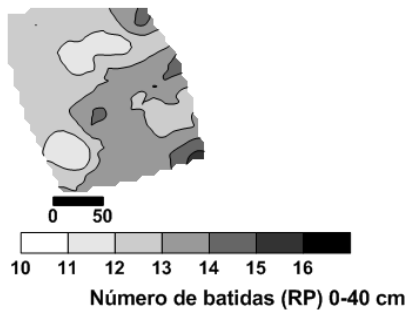

$\mathrm{f}$ - Degradado

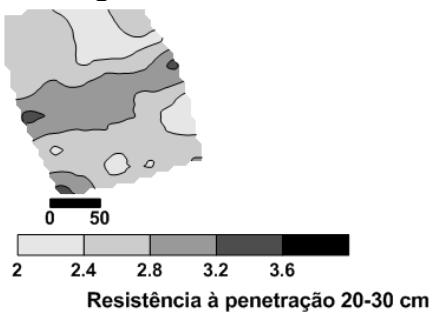

i - Degradado

Figura 2. Mapas das variáveis interpoladas por krigagem que apresentaram dependência espacial no nível não degradado da pastagem: a - infiltração de água no solo a $10 \mathrm{~cm} ; \mathrm{b}$ - número de batidas; c resistência à penetração de 20-30; d - resistência à penetração $30-40 \mathrm{~cm}$. No nível degradado da pastagem: e - infiltração de água no solo a $10 \mathrm{~cm}$; $\mathrm{f}$ - número de batidas; $\mathrm{g}$ - resistência a penetração de $0-10 ; \mathrm{h}$ - resistência à penetração de $10-20 ; \mathrm{i}$ - resistência à penetração de $20-30 ; j$ - resistência à penetração de $30-40 \mathrm{~cm}$.

Apesar de serem áreas diferentes, de acordo com os mapas de krigagem, verifica-se a existência de valores maiores da taxa de infiltração de água na pastagem não degradada comparada com a área de pastagem degradada, e o número de batidas para atingir a camada mais profunda ao longo das áreas foi menor na pastagem não degradada. Pode-se observar na Figura 2, que seguindo uma escala semelhante, o mapa de batidas (Figura 2b) na pastagem não degradada é nitidamente mais claro do que o da pastagem degradada (Figura 2f), ou seja, apresenta valores menores distribuídos espacialmente na área. Este resultado reforça o entendimento seguido por Miguel et al (2009), de que o manejo do pasto com destaque possivelmente para o controle da degradação da pastagem, pode ter influência sobre a sustentabilidade da atividade pecuária quanto à conservação do solo e conseqüentemente em termos econômicos.

Os mapas da Figura 2 representam espacialmente como são distribuídos os atributos estudados ao longo da área e apresentam manchas com maiores valores concentradas em determinadas regiões das áreas. Estes resultados podem ser decorrentes de alguma outra variação espacial referente ao solo. Para que se possa averiguar a causa desta variabilidade espacial ocorrida no solo sob pastagem degradada e não degradada, outras investigações seriam necessárias nestas áreas de estudo. Considerando-se os mapas na área não degradada (Figuras $2 \mathrm{a}$ até $2 \mathrm{~d}$ ) e na área degradada (Figuras $2 \mathrm{e}$ até $2 \mathrm{j}$ ), notam-se 
muitas semelhanças dentro deles. Manchas de maiores valores de infiltração de água no solo correspondem às de menor resistência à penetração principalmente para área de pastagem degradada, o que leva ao entendimento de que seria possível usar mapas de atributos do solo para selecionar locais onde se pode identificar a degradação de pastagem e onde o manejo pode ser recomendado para a recuperação destas áreas degradadas. Este entendimento foi feito em muitos outros trabalhos, como o de Vieira et al (2008) para a seleção de local para experimento de competição de variedades de cana-deaçúcar. Outro importante entendimento é que estes mapas podem ajudar o planejamento do manejo sustentável das pastagens, por possibilitar a construção de mapas que permitem a avaliação dos efeitos da degradação da pastagem sobre os atributos físicos do solo.

\section{Conclusão}

Para a área com pastagem degradada, tanto a infiltração de água no solo, quanto os atributos referentes à resistência do solo à penetração apresentaram estrutura de dependência espacial. Na pastagem não degradada também houve dependência espacial para a infiltração de água no solo, entretanto para a resistência a penetração houve dependência somente nas camadas mais profundas de $20-40 \mathrm{~cm}$.

Áreas com maiores valores de infiltração de água no solo distribuídas espacialmente correspondem às de menor resistência à penetração, indicando que seria possível usar mapas de atributos do solo para selecionar locais onde se pode identificar a degradação de pastagem e onde o manejo pode ser recomendado para a recuperação das áreas degradadas.

\section{Agradecimento}

Ao Conselho Nacional de Desenvolvimento Científico e Tecnológico (CNPq), pelo auxílio à pesquisa (processo 577174/2008-8).

\section{Referências}

EMBRAPA. Centro Nacional de Pesquisa de Solos (Rio de Janeiro, RJ). Sistema Brasileiro de Classificação de Solos. Brasília: Embrapa Produção da Informação; Rio de Janeiro: Embrapa Solos, 1999. 412p.

GOLDEN SOFTWARE. Surfer 7.0: contouring and 3D surface mapping for scientists and engineers: user's guide. New York: Golden Software, 1999. 619p.

GOMES, F.P. Curso de estatística experimental. Piracicaba: ESALQ/USP, 2000. 477p.

LANZANOVA, M.E.; NICOLOSO, R. da S.; LOVATO, T.; ELTZ, F.L.F.; AMADO, T.J.C.; REINERT, D.J. Atributos físicos do solo em sistema de integração lavoura pecuária sob plantio direto. Rev. Bras. Ci. Solo, 31, p.1131-1140, 2007.

MIGUEL, F. R. M.; VIEIRA, S. R.; GREGO, C. R. Variabilidade espacial da infiltração de água em solo sob pastagem em função da intensidade de pisoteio. Pesq. Agropec. Bras. 44, p. 1513-1519, 2009

NASCIMENTO JR., D.; QUEIROZ, D.S.; SANTOS, M.V.F. Degradação das pastagens e critérios para avaliação. In: SIMPÓSIO SOBRE MANEJO DAS PASTAGENS, 11, 1994 Anais... Piracicaba: Fundação de Estudos Agrários Luiz de Queiroz, 1994. p.107-151.

SOUZA, Z. M.; MARQUES JUNIOR, J.; PEREIRA, G. T. Otimização amostral de atributos de latossolos considerando aspectos solo-relevo. Ci. Rural,v. 36, p.829-836, 2006.

STOLF, R. Teoria e teste experimental de fórmulas de transformação dos dados de penetrômetro de impacto em resistência do solo. Rev. Bras. Ci. Solo. v.15, p.229-235, 1991.

VIEIRA, S. R. Uso de geoestatística em estudos de variabilidade espacial de propriedades do solo. In: NOVAIS, R. F. (Ed.). Tópicos em Ciência do Solo 1, Sociedade Brasileira de Ciência do Solo, Viçosa, p. 387, 2000.

VIEIRA, S. R.; MILLETE, J. A.; TOPP, G. C.; REYNOLDS, W. D. Handbook for Geostatistical analysis of variability in soil and meteorological parameters. In: ALVAREZ, V. H. (Ed.). Tópicos em Ciência do Solo 2, Sociedade Brasileira de Ciência do Solo, Viçosa, p 1-45, 2002.

VIEIRA, S.R. Permeâmetro: novo aliado na avaliação de manejo do solo. 0 Agronômico, v.47-50, p.32 -33, 1998.

VIEIRA, S.R.; XAVIER, M. A; GREGO, C. R. Aplicações de geoestatística em pesquisa com cana-deaçúcar. In: MIRANDA-DINARDO, L. L.; VASCONCELOS, A C. M.; LANDELL, M. G. A (Eds.). Cana-deaçúcar, Campinas: Instituto Agronômico, 2008. p. 839- 852. 